\title{
Sediment dynamics in a sand bed stream with riparian vegetation
}

\author{
Sam Gorrick ${ }^{1}$ and José F. Rodríguez ${ }^{1,2,3}$ \\ Received 9 June 2011; revised 5 January 2012; accepted 9 January 2012; published 7 February 2012.
}

[1] The characteristic bed morphology of streams results from the action of various sediment fluxes. Sediment fluxes are difficult to quantify, and as a result, few studies have been able to characterize the relative importance of different transport mechanisms in shaping a river's bed at the reach scale. Even fewer studies have been able to address the impacts of introduced riparian vegetation on those fluxes. This study provides the first comprehensive set of flow and sediment measurements required to compute the fluxes in a sand bed stream with riparian vegetation. Data were collected in a reduced-scale laboratory model of a reach of a sand bed stream in southeastern Australia that is undergoing rehabilitation using in-stream riparian vegetation. The reach has a large-radius meander and a variable width. Laboratory measurements included streamwise and transverse velocities, bed shear stresses, bed load transport, suspended sediment concentrations, and bed topography with and without riparian vegetation placed along the outer bank of the bend. The results unveiled the importance of secondary circulation as well as converging and diverging flow patterns in shaping the bed topography. Modifications due to the vegetation included a shift of the main flow away from the vegetated outer bank and an overall straightening of the flow in the reach, resulting in an increased deposition near the vegetated bank and a reduced deposition near the inner bank. This highlights the need for overall reach assessment of flow and sediment dynamics before revegetation, as its effects go beyond local bank protection.

Citation: Gorrick, S., and J. F. Rodríguez (2012), Sediment dynamics in a sand bed stream with riparian vegetation, Water Resour. Res., 48, W02505, doi:10.1029/2011WR011030.

\section{Introduction}

[2] Fluxes of bed and suspended sediment generate the characteristic morphology of movable bed streams over time. Sand bed streams carry a mixture of bed and suspended load and the relative importance of particular sediment fluxes in shaping specific aspects of the stream morphology changes for different configurations. For example, transverse diffusion of suspended sediment is fundamental to the maintenance of a stable cross section in straight sand bed streams [Parker, 1978]. On the other hand, meandering streams display convective transverse sediment fluxes resulting from secondary circulation that contribute to the bar pool topography characteristic of river bends [Ikeda and Nishimura, 1985]. Width variations in braided streams control longitudinal and transverse fluxes of bed load and suspended load that determine the size and position of central bars at bifurcations [McLelland et al., 1999; Repetto et al., 2002].

\footnotetext{
${ }^{1}$ Civil, Surveying and Environmental Engineering, University of Newcastle Australia, Callaghan, New South Wales, Australia.

${ }^{2}$ Centro Universitario Rosario de Investigaciones Hidroambientales, Rosario, Argentina.

${ }^{3}$ Departmento de Hidráulica, Universidad Nacional de Rosario, Rosario, Argentina.
}

Copyright 2012 by the American Geophysical Union 0043-1397/12/2011WR011030
[3] Riparian vegetation is a common feature of sand bed streams and recent studies have demonstrated that its impact goes beyond local bank or bar stabilization, affecting overall sediment dynamics and reach-scale stream morphology [Yuuki and Okabe, 1997; Gran and Paola, 2001; Bennett et al., 2008; Rominger et al., 2010]. Suspended sediment fluxes are perhaps the most affected by the presence of vegetation. Some studies suggest that bank vegetation and bank protection structures increase lateral diffusion of suspended sediment because of stronger velocity and concentration gradients [Ikeda et al., 1991; Sharpe and James, 2006] with large-scale vortices also contributing to sediment transport in this near bank zone [Shimizu and Tsujimoto, 1997]. Within the vegetated zone, suspended sediment fluxes are strongly affected, both by increased settling due to reduced flow velocities [Sharpe and James, 2006; Zong and Nepf, 2010] and by reduced entrainment due to dampened bed shear stresses [Lopez and Garcia, 1998].

[4] The presence of vegetation also influences bed load transport. If bed load is considered a power function of bed shear stress, reduced bed shear stresses due to vegetation drag result in even greater reductions in bed load transport. Experiments by Jordanova and James [2003] and Okabe et al. [1997] confirmed that standard bed load predictions can be extended to vegetated flows as long as the corresponding reductions in shear stress due to vegetative drag are accounted for. 
[5] Vegetation can also affect stream alignment by deflecting flow. If the obstruction posed by riparian vegetation is large enough relative to channel width, the deflection of flow can initiate meandering, similar to the effect of a point bar [Bennett et al., 2002]. Flow deflection away from the vegetation generates a bar pool topography which reinforces the meandering flow pattern [Bennett et al., 2008]. Conversely, continuous narrow strips of outer bank vegetation may dampen the asymmetry of meandering flows and reduce the downstream skewness of high velocities and bend migration [Thorne and Furbish, 1995; Perucca et al., 2007].

[6] The above results show that riparian vegetation, through the redistribution of bed shear stresses and velocities, can have numerous effects on sediment transport and river morphology depending on the type of river and the density and spatial distribution of the vegetation. To date, only a partial understanding of the different transport mechanisms that interact to determine the stream morphology in the presence of riparian vegetation has been achieved, mostly on the basis of simplified geometries and with a clear focus on the near bank zone. This paper investigates reach-scale sediment dynamics, which comprise sediment fluxes and the resulting stream morphology, in a sand bed stream of southeastern Australia. The stream is currently being restored with in-channel bank vegetation, including fast growing woody tree species such as Casuarina cunninghamiana, commonly known as River Oak. A laboratory experiment on flow and sediment transport was carried out on a reduced-scale model of the stream reach using no vegetation followed by an experiment with in-channel bank vegetation, representing the restoration works at an established stage when the vegetation may be considered rigid and emergent. This unique data set has allowed attempting for the first time a thorough analysis of the dominant sediment fluxes in a typical sand bed stream with natural morphology, their influence on the development of bed topography over time, and their interaction with bank vegetation. The results are not only valuable from a strictly scientific point of view but are also relevant to the design of river restoration projects using riparian revegetation.

\section{Sediment Transport in Mixed Load Streams}

[7] The sand bed stream in the field has both suspended transport and bed load transport, thus can be considered a mixed load stream. In what follows, Exner's equation is adapted in order to explain mechanisms for bed elevation changes over time in sand bed streams similar to the one being studied. Exner's equation for the conservation of sediment in the bed (in volumetric form) can be written as [Garcia, 2008]

$$
\left(1-\lambda_{p}\right) \frac{\partial \eta}{\partial t}+\frac{\partial q_{b s}}{\partial s}+\frac{\partial q_{b n}}{\partial n}+E_{b}-D_{b}=0,
$$

where $\lambda_{p}$ is the sediment porosity, $\eta$ is the bed elevation, $t$ is time, $q_{b s}$ and $q_{b n}$ are volumetric bed load fluxes per unit width in the downstream $s$ and cross-stream $n$ directions, respectively, and $E_{b}-D_{b}$ is the suspended sediment flux at the bed, composed of entrainment $E_{b}$ and depositional $D_{b}$ fluxes. The suspended sediment flux is also a boundary condition for the suspended sediment conservation equation, whose depth-integrated version can be written as [Parker, 1978; Ikeda et al., 1991]

$$
\begin{aligned}
& \frac{\partial \bar{C} H}{\partial t}+\frac{\partial}{\partial s}\left(\overline{C U} H-\varepsilon_{s} \frac{\partial \bar{C} H}{\partial s}\right)+\frac{\partial}{\partial n}\left(\overline{C V} H-\varepsilon_{n} \frac{\partial \bar{C} H}{\partial n}\right) \\
& \quad=-E_{b}+D_{b},
\end{aligned}
$$

where $C$ is the concentration of suspended sediment (averaged over turbulence) $H$ is the water depth, $U$ and $V$ are velocities in the $s$ and $n$ directions, respectively (averaged over turbulence), and $\varepsilon_{s}$ and $\varepsilon_{n}$ are kinematic eddy diffusivity coefficients in the same respective directions. Overbars indicate depth-averaged quantities. Assuming steady state conditions and fully developed flow and concentration profile, the suspended sediment conservation reduces to

$$
\bar{C} \frac{\partial}{\partial s}(\bar{U} H)+\frac{\partial}{\partial n}\left(\overline{C V} H-\varepsilon_{n} \frac{\partial \bar{C} H}{\partial n}\right)=-E_{b}+D_{b}
$$

if it is further assumed that $H \gg \eta$, the combination of the previous equation with the Exner's equation results in

$$
\begin{aligned}
\underbrace{\left(1-\lambda_{p}\right) \frac{\partial \eta}{\partial t}=}_{\text {Term A }} & \bar{C} \underbrace{\frac{\partial}{\partial s}(-\bar{U} H)}_{\text {Term B }}+\underbrace{\frac{\partial}{\partial n}\left(-\overline{C V_{1}} H\right)}_{\text {Term C1 }}+\underbrace{\frac{\partial}{\partial n}\left(-\overline{C V_{2}} H\right)}_{\text {Term C2 }} \\
& +\underbrace{\frac{\partial}{\partial n}\left(\varepsilon_{n} \frac{\partial \bar{C}}{\partial n}\right)}_{\text {Term D }}-\underbrace{\frac{\partial q_{b s}}{\partial s}-\frac{\partial q_{n s}}{\partial n}}_{\text {Term D }} .
\end{aligned}
$$

[8] This equation states that the rate of sedimentation or erosion (term A) is equal to spatial gradients in the downstream suspended sediment flux (term B), cross-stream convective flux (term C) transverse diffusive flux (term D) and in bed load transport (term E). The cross-stream convective flux consists of a primary and secondary component (terms $\mathrm{C} 1$ and $\mathrm{C} 2$, respectively) because of the superposition of diverging or converging flow denoted by $V_{1}$ and secondary circulation denoted by $V_{2}$. The relative importance of the $\mathrm{C} 1$ and $\mathrm{C} 2$ terms will change depending on the channel configuration. In a bend, term $\mathrm{C} 2$ will increase because of stronger secondary circulation. As a channel widens or contracts, term $\mathrm{C} 1$ will increase because of the divergence or convergence of flow. Using experimental data and equation (4), the relative importance of different sediment fluxes in shaping bed morphology is addressed in section 4 .

\section{Methods}

\subsection{Laboratory Model}

[9] The measurements were conducted in a 1:16 lengthscale Froude similarity model of a $200 \mathrm{~m}$ reach of the Widden Brook, in southeastern Australia. The Widden Brook is a low-sinuosity, single-channel sand bed stream with a continuous narrow floodplain set in a sandstone valley. 
Historically, the channel has enlarged in width because of a series of large floods in the 1950s resulting in the current channel being wide and shallow. The bed slope measured from a longitudinal survey extending $1 \mathrm{~km}$ upstream and downstream of the reach is 0.002 . In the selected reach, bed sediment consists of poorly sorted coarse sand with a mean diameter of $0.8 \mathrm{~mm}$. Dunes have been observed on the streambed during low flow. The channel has a large radius meander bend as well as significant variation in channel width (Figure 1). The channel gets wider at the bend, with the free surface width up to $25 \%$ larger at the bend apex than at the inflection points. There is a tendency for increased bed scour at the narrow inflection points and deposition in the wider bend section. The minimum radius of curvature is $30 \mathrm{~m}$, the free surface width ranges from 24 to $30 \mathrm{~m}$ and the width to depth ratio changes from 25 to 30 . The reach is also undergoing a trial revegetation program which has planted mostly woody riparian vegetation along the outer (left) bank of the bend.

[10] The model was set up in a tilting flume (Figure 1) by carving the field topography into polystyrene blocks placed between guiding cross sections $0.3 \mathrm{~m}$ apart. The flume had a total length of $13 \mathrm{~m}$ and a width of $2 \mathrm{~m}$. Flow was powered by a centrifugal pump and monitored with an electromagnetic flowmeter. Two fixed point gauges were mounted at either end to monitor the water surface slope. A movable carriage mounted on the flume rails fitted with a transverse and vertical lead screw positioning device was used to position measuring instruments (Figure 1). Two experiments were carried out, MB1 on the existing bed topography without vegetation, and MB2 on the same topography but including vegetation arranged following the design of the field revegetation trial. Once the model was set up, the measurements were conducted in two separate stages. In the first stage, flow velocity and water surface elevation data were collected under fixed bed conditions. In the second stage, a sediment feed was introduced and sediment transport measurements were collected over a mobile bed.

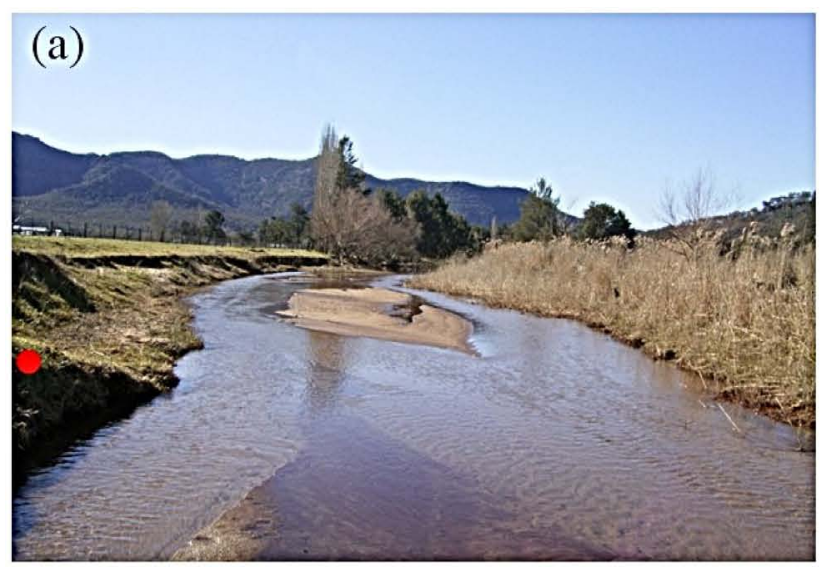

\subsection{Fixed Bed Stage}

[11] A steady bankfull flow rate of $49.5 \mathrm{~L} \mathrm{~s}^{-1}$ was adopted after downscaling flow records from the field site. Sand grains of $0.8 \mathrm{~mm}$ diameter were glued to the model surface, in order to provide equivalent roughness conditions to the field site. A weir placed at the downstream end was adjusted to achieve uniform flow conditions, wherein the average slope of the water surface was parallel to the average bed slope [Rodríguez and García, 2008]. The water surface slope was obtained from the two fixed point gauges and a third movable gauge attached to the carriage. The conditions during the fixed bed experiments are summarized in Table 1.

[12] Flow measurements included water surface elevations and 2-D instantaneous velocities at three cross sections spaced $1.24 \mathrm{~m}$ apart (XS20, XS24, and XS28). Velocities were measured with a 2-D ADV because of the shallow flow conditions. In each cross section, vertical velocity profiles were spaced at $10 \mathrm{~cm}$ intervals and had a 1 $\mathrm{cm}$ vertical resolution. At each point, measurements were carried out for $2 \mathrm{~min}$ at $25 \mathrm{~Hz}$ frequency, ensuring reliable estimates of mean flow and first-order turbulence statistics. The water surface elevation was measured at each vertical with the movable point gauge. Note that additional measurements were recorded at 18 other cross sections in the model which are presented by Gorrick [2011].

\subsection{Mobile Bed Stage}

[13] During the second stage of experiments over a mobile bed, a steady bankfull flow rate of $49.5 \mathrm{~L} \mathrm{~s}^{-1}$ was used in conjunction with a dry sediment feed $\left(Q_{f}\right)$ of $165 \mathrm{~g} \mathrm{~s}^{-1}$. The feed rate was based on the predictions of the Engelund and Hansen [1967] relation for total sediment load which assumes transport limited conditions and a median particle size $\left(D_{50}\right)$ less than $1 \mathrm{~mm}$.

[14] The scaling of sediment in the mobile bed experiments aimed at achieving a similar range of mobility to that of the field sediment. Because of the scale of the physical model $(1: 16)$ similar mobility levels could only be

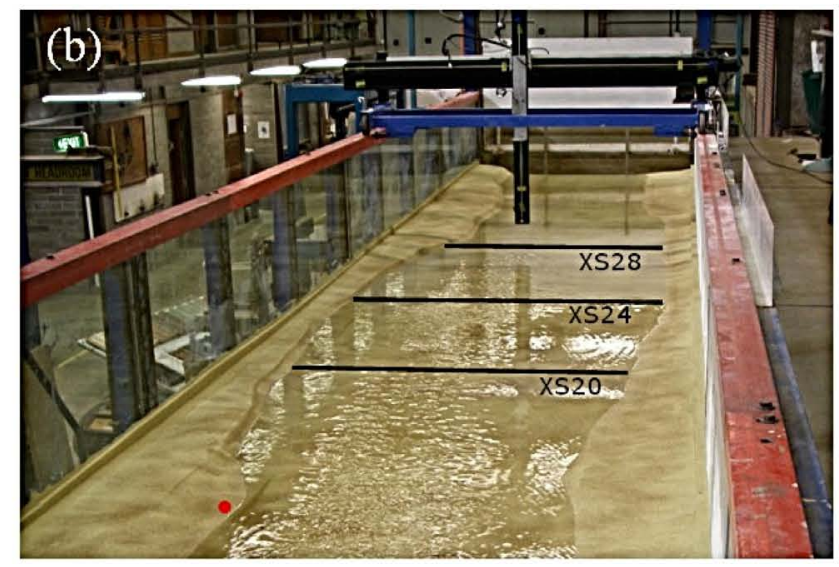

Figure 1. Field site along with the reduced-scale model. (a) Field site looking downstream into the large radius bend during low flow, 13 May 2005. (b) Laboratory model of the field site also looking downstream. Notice the red dots indicate a similar position in the field and laboratory. Also shown are the position of three cross sections in which measurements were taken and, a little farther downstream, the movable carriage used to position instruments. 
Table 1. Hydraulic Conditions at Three Cross Sections During the Fixed and Mobile Bed Measurement Stage for MB1

\begin{tabular}{|c|c|c|c|c|c|c|c|c|c|}
\hline & $Q\left(\mathrm{~L} \mathrm{~s}^{-1}\right)$ & $S_{w}$ & $S_{b}$ & $\begin{array}{c}k_{s} \\
(\mathrm{~mm})\end{array}$ & $\begin{array}{c}A \\
(\mathrm{~m})\end{array}$ & $\begin{array}{l}R_{h} \\
(\mathrm{~m})\end{array}$ & $\begin{array}{c}B \\
(\mathrm{~m})\end{array}$ & $\begin{array}{l}R_{c}^{\mathrm{a}} \\
(\mathrm{m})\end{array}$ & $\begin{array}{c}\langle U\rangle^{\mathrm{b}} \\
\left(\mathrm{m} \mathrm{s}^{-1}\right)\end{array}$ \\
\hline \multicolumn{10}{|c|}{ Fixed Bed } \\
\hline $\mathrm{XS} 20$ & 49.5 & 0.002 & 0.002 & 0.8 & 0.093 & 0.053 & 1.70 & -8.0 & 0.53 \\
\hline XS24 & 49.5 & 0.002 & 0.002 & 0.8 & 0.104 & 0.058 & 1.88 & -4.0 & 0.48 \\
\hline XS28 & 49.5 & 0.002 & 0.002 & 0.8 & 0.092 & 0.055 & 1.61 & 2.0 & 0.54 \\
\hline \multicolumn{10}{|c|}{ Mobile Bed } \\
\hline XS20 & 49.5 & 0.003 & 0.003 & 3.0 & 0.102 & 0.059 & 1.78 & -8.0 & 0.48 \\
\hline $\mathrm{XS} 24$ & 49.5 & 0.003 & 0.003 & 2.4 & 0.110 & 0.062 & 1.95 & -4.0 & 0.45 \\
\hline $\mathrm{XS} 28$ & 49.5 & 0.003 & 0.003 & 2.4 & 0.098 & 0.058 & 1.64 & 2.0 & 0.51 \\
\hline
\end{tabular}

${ }^{\mathrm{a}} R_{c}<0$ indicates a bend toward the left when looking downstream.

${ }^{\mathrm{b}}\langle U\rangle=Q / A$ and represents a cross-sectional average velocity in the downstream direction.

achieved with light-weight sediment, in this case a mixture of coal (for the finer fractions between 0.3 and $0.8 \mathrm{~mm}$ ) and crushed apricot pip (for the coarser fractions between 0.8 and $2 \mathrm{~mm}$ ) each with the same submerged specific gravity $(\mathfrak{R}=0.3)$. Both materials have been successfully used in the past for scaled sediment transport experiments [Bettess, 1990]. A size distribution of the light sediment very similar to the field distribution was adopted (Figure 2) in order to maintain values of the Shields parameter $\tau^{*}=\tau_{b} / \rho g \mathfrak{R} D_{j}$ ( $\tau_{b}$ is the bed shear stress, $\rho$ is the fluid density, $g$ is the gravitational acceleration, $D_{j}$ is the grain size), and the particle Reynolds number $\operatorname{Re}_{\mathrm{p}}=D_{j} \sqrt{\mathfrak{R} g D_{j}} / v$ ( $v$ is the kinematic viscosity), within a reasonable range of the observed field values. This resulted in the field and laboratory sediments plotting very close in the Shields regime diagram [García, 1999], as can be seen in Figure 3. Bed shear stresses in the field were obtained using the depth slope product and flow measurements presented elsewhere [Gorrick, 2011], while laboratory bed shear stresses were obtained from flow measurements presented in section 4 . Figure 3 also depicts a range of sediment transport regimes for natural rivers, which depend on $\tau^{*}$ and $R e_{\mathrm{p}}$. The regimes are separated by thresholds that include viscous effects and determine ripple or dune bed forms

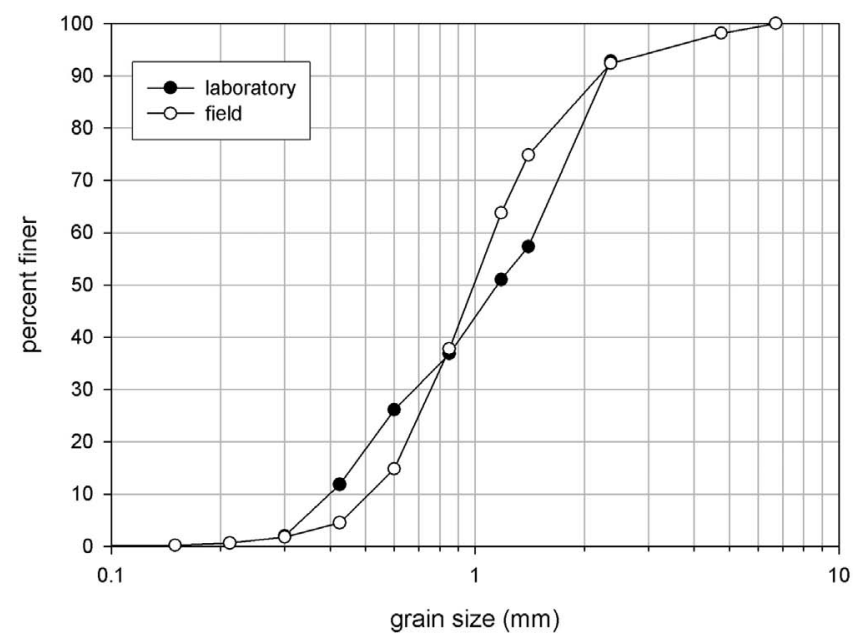

Figure 2. Size distribution of bed sediment at the field site and in the laboratory sediment feed for the mobile bed experiments.

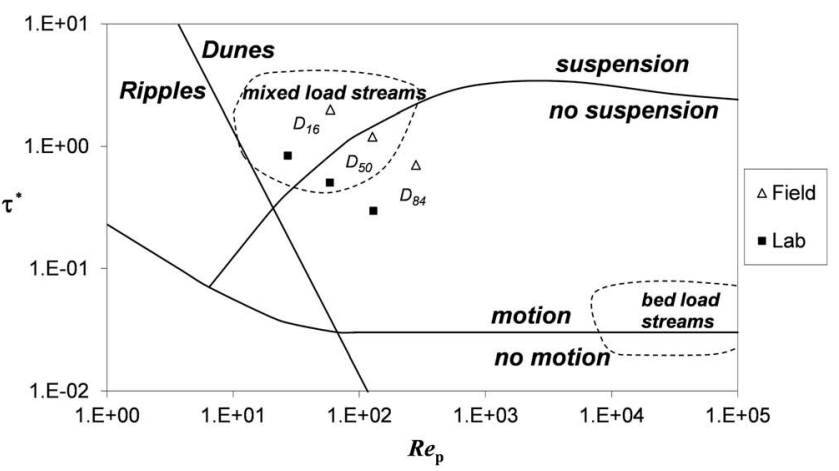

Figure 3. Bankfull Shield's regime diagram modified from Garcia [1999]. Data points correspond to $\tau^{*}$ and $R e_{\mathrm{p}}$ values for different grain sizes at the field site and in the laboratory model. The solid lines delineate sediment transport regimes, and the dashed lines indicate the typical range of values for mixed and bed load streams obtained from Dade and Friend [1998].

$\left(\tau^{*}=\left(11.6 / R_{e p}\right)^{2}\right)$, suspension $\left(\tau^{*}=\mathfrak{R} g D_{s} / W_{s}^{2} ; W_{s}\right.$ is the sediment fall velocity) and incipient motion $\left(\tau^{*}=0.05\right)$. As Figure 3 predicts, dunes migrated through the channel in all our experiments. Even though the match between $\tau^{*}$ and $R e_{\mathrm{p}}$ in field and laboratory is not exact, the laboratory data plots within the range of other mixed load streams [Dade and Friend, 1998] and with a proportion of material in suspension comparable to that of the field.

[15] The mobile bed experiments began by establishing steady uniform flow which was identical to flow in the fixed bed measurement stage, after which the sediment feed was started. The sediment was manually fed into the channel at regular $7 \mathrm{~s}$ intervals. The accuracy of the sediment feed was tested prior to experimentation using a load cell and stopwatch, with the manual feed always producing values within $10 \%$ of the desired feed rate. Sediment at the downstream end was captured in a filter basket and retrieved after each experiment for reuse. Typically, the mobile bed had reached steady thickness after a 10 min period which was taken as an indication of equilibrium (Figure 4). This short time scale for steady state to develop was probably due to the high mobility of lightweight sediments. Bed mobility has been identified as one of the most important factors in determining the time scale of equilibrium in mobile beds [Binns and da Silva, 2009]. After a further $20 \mathrm{~min}$ all

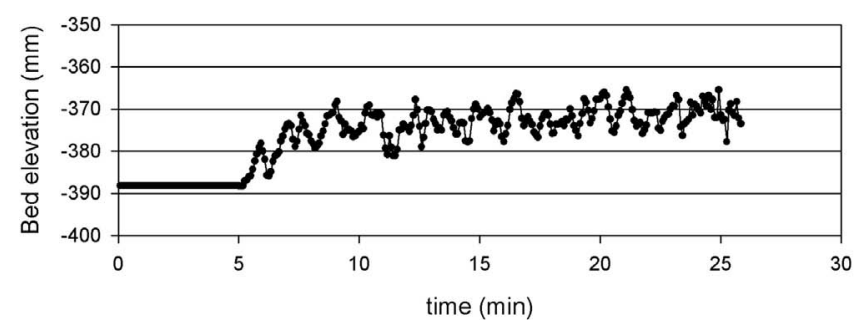

Figure 4. Time series of bed elevation near the center of XS24 during MB1. Time at 0 min corresponds to the introduction of the sediment feed. Notice the rapid development of bed forms after $5 \mathrm{~min}$ and the steady state after $10 \mathrm{~min}$. 
sediment had been fed into the channel. In this 20 min period the water surface slope was measured between the two fixed point gauges. At three cross sections, measurements of sediment transport and water surface elevation were recorded. Because of the short duration of the sediment feed (30 $\mathrm{min})$, six runs were required to complete measurements of both suspended and bed sediment at the three cross sections. Repeatability was examined by taking extra runs at the same cross section and comparing the results. Bed load was calculated with measurements of dune migration made using a stationary $5 \mathrm{MHz}$ Seatek ultrasonic profiler sampling at $1 \mathrm{~Hz}$. The bed profiler consisted of 24 transducers spaced $4 \mathrm{~cm}$ apart, which were just submerged during each experiment. The threshold voltage was adjusted from its default setting to $400 \mathrm{mV}$ to minimize interference from the suspended load. The depth average suspended sediment concentration $\bar{C}$ was measured with isokinetic samples of the water column. Each sample collected between 600 to $700 \mathrm{~mL}$ over 40 to $50 \mathrm{~s}$. This sample time ensured a reasonable time average given the time required for dunes to pass a fixed point was between 20 and $50 \mathrm{~s}$. During a run, samples were collected at $10 \mathrm{~cm}$ intervals across the channel, giving at least 10 samples in each section. Water from the samples was drained and the suspended sediment was dried and weighed.

[16] The hydraulic conditions present at the three cross sections during the fixed and mobile bed measurement stages of MB1 are shown in Table 1, where some differences in the conditions between the two stages can be observed. These include an increase in grain roughness due to the presence of larger diameter grains in the sediment feed compared with glued sand grains in the fixed bed stage. The contribution of dunes and grains to the total shear stress was estimated using the partition method of Nelson and Smith [1989] presented by Garcia [1999]. Assuming a dune measuring $0.01 \mathrm{~m}$ in height and $0.5 \mathrm{~m}$ in length, which is representative of the largest bed forms observed in the model and the grain roughness listed in Table 1, it is estimated that dunes contributed a maximum of $30 \%$ of the total shear stress. Although not included in Table 1, similar values were obtained for the MB2 experiments.

[17] As well as an increase in bed roughness, an increase in the water surface slope was also observed in the mobile bed measurement stage which was accompanied by a similar increase in the bed slope. Despite the increase in bed roughness, cross-sectional average velocity remains similar in the two stages with slight decreases during the mobile bed stage of $10 \%, 5 \%$, and $6 \%$ in XS20, XS24, and XS28, respectively. This is because the increased bed roughness was compensated by an increase in the water surface slope, resulting in similar velocities in the two stages of experimentation. For this reason no attempts were made to freeze the mobile bed and retake the flow velocity measurements. Furthermore, channel curvature at each cross section remains unchanged and there is a similar expansion in flow width between XS20 and XS24 and contraction between XS24 and XS28. Since downstream and cross-stream velocities remained similar during the mobile bed stage, they were combined with measured concentrations to evaluate the suspended fluxes and terms B, C, and D in equation (4) for both the MB1 and MB2 experiments.

\subsection{Experiments With Bank Vegetation}

[18] As already explained, the same set of conditions and measurements in fixed and mobile bed stages were repeated with simulated vegetation during the MB2 experiments. The simulated vegetation consisted of rigid dowel rods, $6 \mathrm{~mm}$ in diameter, which were inserted into the polystyrene model. Each dowel rod was cut to a length larger than the flow depth to simulate mature emergent vegetation. The dowels were arranged in three patches along the face of the outer bank (Figure 5) resembling the arrangement used in works currently underway in the field but at an advanced stage of growth. Within each patch, the dowels were arranged in a staggered pattern with a frontal area density of $3.33 \mathrm{~m} \mathrm{~m}^{2} \mathrm{~m}^{-2}$ and an average spacing of $4 \mathrm{~cm}$. This spacing was determined by the density of planting at the field site and the length scale of the model. The same hydraulic conditions as in the experiments without vegetation were maintained (Table 1). To aid visualization of both experiments, Figure 6 shows the bare outer bank in MB1 and the vegetation configuration in $\mathrm{MB} 2$ side by side. The different bed topographies in MB1 and MB2 in Figure 6 are explained in subsequent results.

\subsection{Data Processing and Analysis}

[19] Measured velocity vectors of the fixed bed conditions were decomposed into streamwise and cross-stream projections. First, velocities in each cross section were oriented to obtain zero lateral discharge [Lane et al., 1998] so as to align the streamwise component of velocity with the local flow direction. The local flow direction deviated only slightly from the original cross-section orientation shown

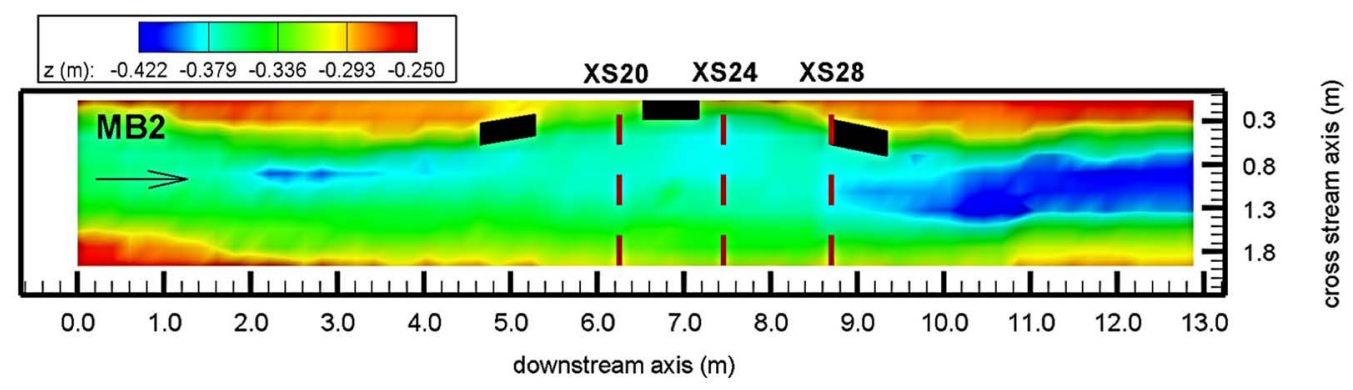

Figure 5. Plan view of the model topography and the configuration of in-channel bank vegetation patches (shown in black) used in MB2. Note that the model topography was identical in MB1. 


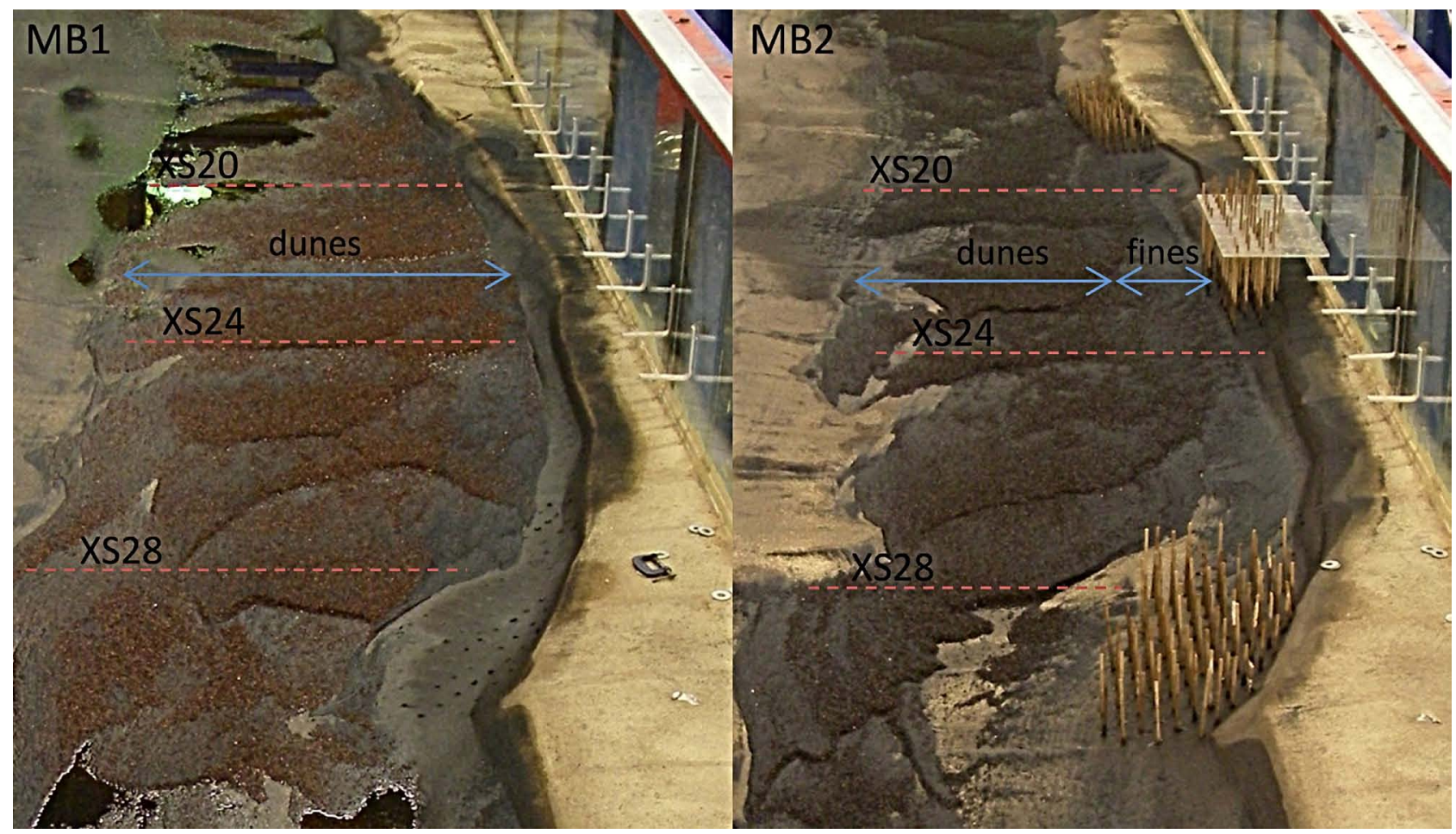

Figure 6. Bed topography at the conclusion of MB1 and MB2. Each photograph was taken looking upstream, so the left bank appears on the right. In MB2, there is a zone of fine sediment running alongside the left bank, whereas dunes extend to the base of the left bank in MB1.

in Figure 5. Because of the presence of both curvature and variation in channel width, cross-stream velocities were split into two components following Rhoads and Kenworthy [1998]. The primary component $\left(V_{1}\right)$ represents divergence or convergence associated with an increase or decrease in channel width, respectively. The secondary component $\left(V_{2}\right)$ represents secondary circulation due to channel curvature. Since no vertical velocity measurements were available to fully determine the secondary circulation patterns, it was assumed that upwelling occurred where $V_{2}$ converged at the bed and diverged near the water surface and that downwelling took place where $V_{2}$ diverged at the bed and converged at the water surface.

[20] Bed shear stress estimates were obtained by maximizing the fit of streamwise velocity profiles to the log law, following Rodríguez and García [2008]. Velocity profiles may depart from the typical log law distribution because of vegetation or other disturbances. However, this was not a problem in the MB2 experiment as cross sections were located between vegetation patches (Figure 5) with the log law providing a good fit to the velocity measurements.

[21] Some studies suggest that streams with bank vegetation have higher cross-stream diffusion [Sharpe and James, 2006]. The evaluation of its significance in the current experiments required a calculation of term $\mathrm{D}$ in equation (4) and specifically the kinematic eddy diffusivity $\varepsilon_{n}$. Because of an absence of data, the diffusivity of suspended sediment was assumed to be the same as the flow [Wright and Parker, 2004] and was calculated with the cross-stream Reynolds stress $\left\langle u^{\prime} w^{\prime}\right\rangle$ measured during the fixed bed conditions using a gradient type approximation to model the stresses.
[22] Bed profiler data was used to calculate the amplitude and frequency of bed forms in the mobile bed stage, by first performing a $5 \mathrm{~s}$ moving average and then a Fast Fourier Transform (FFT) to obtain the frequency spectra. From each spectrum the peak amplitude $A_{S}$ and frequency $f_{s}$ corresponding to the dominant dune was identified [Gorrick, 2011]. The spectra were also used to obtain signal to noise ratios (SNR), which for most measurements ranged between 10 and 20, verifying the quality of these measurements.

[23] The length of dunes $l_{s}$ was obtained after each experiment. Bed load transport was then estimated as the volume of material transported in the downstream direction per meter width of channel per second using

$$
q_{b}=A_{s} f_{s} l_{s}\left(1-\lambda_{p}\right)
$$

where a value of porosity $\lambda_{p}=0.4$ was used on the basis of experimental determination [Gorrick, 2011].

\section{Results}

\subsection{Flow Measurements}

[24] Figure 7 presents the transverse distribution of the depth averaged downstream velocity, bed shear stress and cross-stream Reynolds stress for the two experiments at each of the three sections obtained during the fixed bed stage. Downstream velocities and shear stresses clearly show that in the vegetated case the flow shifted away from the vegetation zone. As a result, bed shear stresses and downstream flow velocities were higher over the opposite bank to compensate for the decrease in the vegetation zone. 

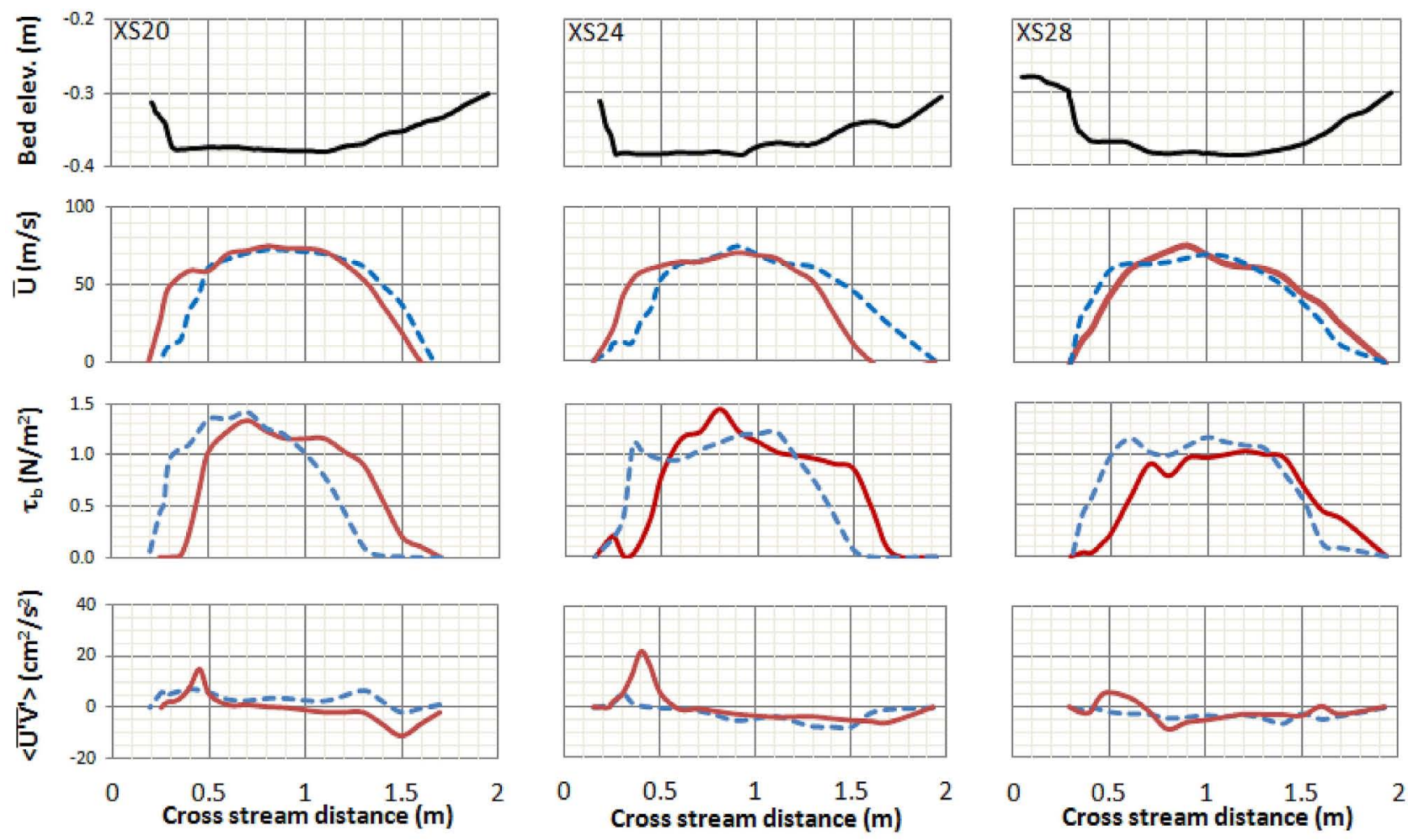

$---M B 1-M B 2$

Figure 7. Flow measurements at XS20, XS24, and XS28 for MB1 and MB2, including downstream depth-averaged velocity, bed shear stress, and cross-stream Reynolds stress.

The vegetated experiment clearly shows the presence of a shear layer between the vegetation zone and the main channel, where Reynolds stresses are higher. The shear layer is developing between XS20 and XS24, and starting to diffuse by XS28.

[25] Cross-stream velocity profiles including secondary circulation and convergence/divergence patterns are shown in Figures 8 and 9 for MB1 and MB2, respectively. Divergence occurs in sections where the channel width expands and consists of a cross-streamflow over the entire depth toward both banks. Convergence occurs in sections where the channel width contracts and consists of a cross-streamflow over the entire depth toward the center of the channel. The $V_{1}$ component showed a marked divergence from XS20 to XS24 followed by convergence from XS24 to XS28 both in the vegetated and unvegetated experiments. This pattern was accompanied by a characteristic centrifugal secondary circulation pattern of $V_{2}$, which was fully established by XS28. The pattern was less well defined in the vegetated experiments, but had the same general features.

\subsection{Bed and Suspended Load Measurements}

[26] Observed sediment transport distributions for all experiments are shown in Figures 10 and 11 together with conventional sediment transport predictions based on flow measurements. Figure 10 shows bed load measurements together with calculated values using the Ashida and Michiue [1972] bed load transport relation,

$$
q_{b}^{*}=17\left(\tau_{s}^{*}-\tau_{c}^{*}\right)\left[\left(\tau_{s}^{*}\right)^{0.5}-\left(\tau_{c}^{*}\right)^{0.5}\right]
$$

where $\tau_{c}^{*}$ is the dimensionless critical shear stress required for motion and is given a value of 0.05 [Ashida and Michiue, 1972] and $\tau_{s}^{*}$ represents the effective shear stress obtained by removing bed form drag as previously explained. Figure 10 also includes results from a repeat of MB1 at XS24 from which a $\pm 30 \%$ measurement error can be obtained. In MB1 the agreement between observed and computed values is not exact but most of the computed values fall within the estimated range of measurement error. A noticeable discrepancy occurs at XS20 where computed values between 0.8 and $1.0 \mathrm{~m}$ along the cross-stream axis far exceed the observed values. A possible explanation is the assumption of unlimited supply in the computed values. In MB 2 the agreement is good at XS20 and XS24; however, observed values at XS28 are higher than the computed values. Although not shown in the results, the measurements at XS28 were accompanied by lower ratios of signal to noise, which was reflected in larger variability in the measurements. The increased noise was due to interference from the suspended sediments, which was a major challenge in the bed load measurements and could not always be overcome.

[27] Measured depth averaged suspended sediment concentrations are presented in Figure 11. Figure 11 also includes a repeat of MB1 at XS24 from which a $\pm 50 \%$ measurement error can be obtained. It is likely that a smaller measurement error could be achieved by increasing the sampling time to include the passage of multiple dunes; however, this was not possible because of time constraints. Computed values were calculated assuming a Rousean 
(a)

\section{XS20}

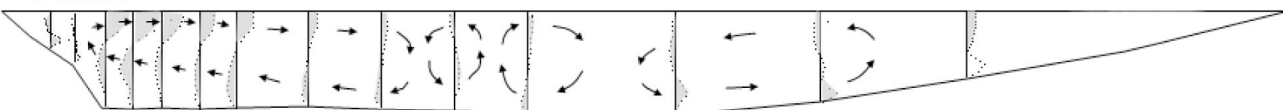

\section{XS24}

\begin{tabular}{|l|l|l|l|l|l|l|l|l|l|l|l|}
\hline \\
\hline
\end{tabular}

\section{XS28}

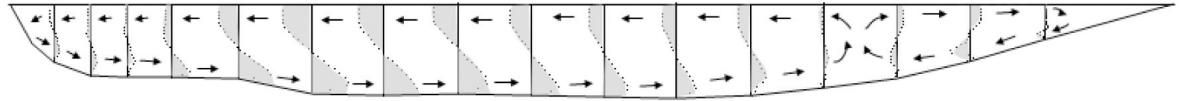

(b)

\section{XS20}

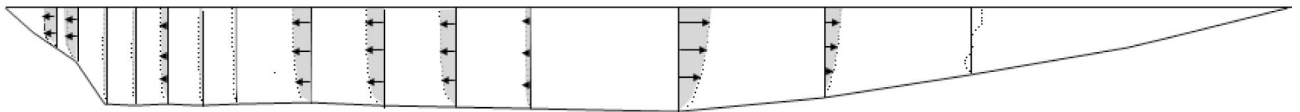

\section{XS24}
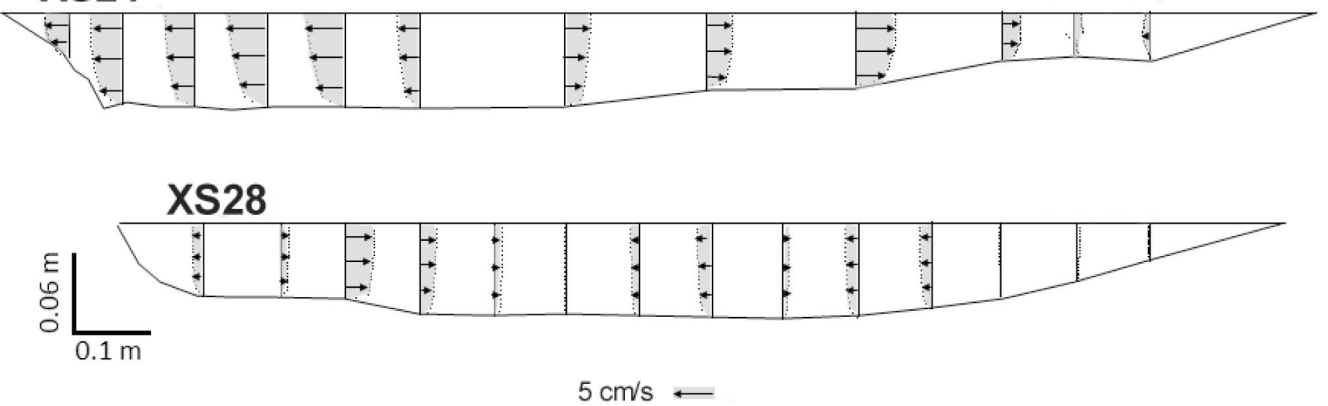

Figure 8. Cross-stream velocity profiles at XS20, XS24, and XS28 for MB1. (a) Secondary circulation. (b) Convergence or divergence velocities.

distribution and the entrainment function of García and Parker [1991] with shear velocities obtained from fixed bed experiments after removing bed form drag. The following series of equations were used to calculate suspended sediment concentration [Garcia, 1999]. First the Rousean equation of concentration $C$ as a function of $z$ is given by

$$
C_{j}(z)=C_{b j}\left[\frac{(H-z) / z}{(H-b) / b}\right]^{P}
$$

where the exponent $P$ is the Rouse number $\left(W_{s j} / \kappa U_{*}\right), C_{b}$ is the near bed sediment concentration, $b$ is a nominal near bed elevation and the subscript $j$ denotes a size fraction of the sediment mixture. For near bed equilibrium conditions deposition and entrainment of sediment are balanced, or in dimensionless terms,

$$
E_{s j}=C_{b}
$$

where $E_{s j}$ is the dimensionless entrainment for a given size fraction and can be estimated with the entrainment function of Garcia and Parker [1991],

$$
E_{s j}=\frac{A_{E} Z_{u j}^{5}}{\left(1+\frac{A_{E}}{0.3} Z_{u j}^{5}\right)}
$$

where $A_{E}=1.3 \times 10^{-7}$ and $Z_{u j}$ is defined by

$$
Z_{u j}=\lambda_{m} \frac{U_{*}}{W_{s j}} \operatorname{Re}_{p j}^{0.6}\left(\frac{D_{j}}{D_{50}}\right)^{0.2}
$$

with $U_{*}$ being the shear velocity, $D_{j}$ the diameter of the subinterval $j, D_{50}$ the median diameter of the mixture and $\lambda_{m}=1-0.288 \sigma_{\phi}$, where $\sigma_{\phi}$ stands for the standard deviation of the sediment distribution on the phi scale. 
(a) $\mathrm{XS20}$
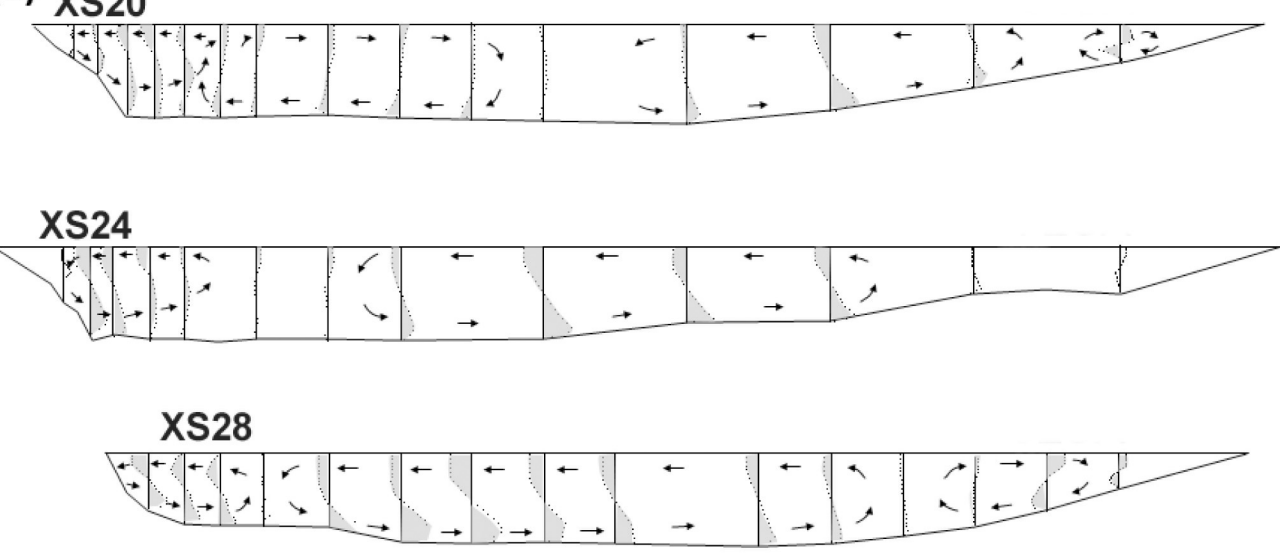

(b)

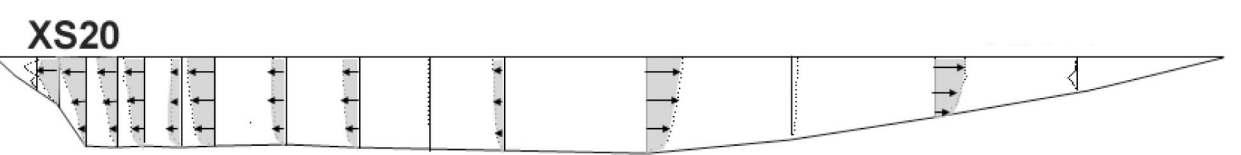

XS24
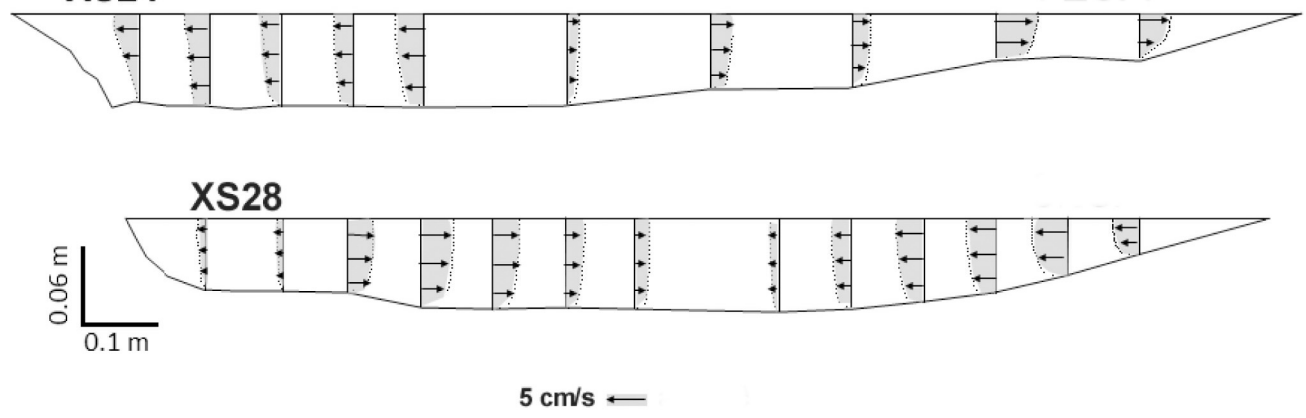

Figure 9. Cross-stream velocity profiles at XS20, XS24, and XS28 for MB2. (a) Secondary circulation. (b) Convergence or divergence velocities.

[28] $C_{j}(z)$ for each class interval may be found by combining equations (7)-(10) and the depth average concentration $\bar{C}_{j}$ by integration,

$$
\bar{C}_{j}=\frac{1}{H} \int_{b}^{H} C_{j}(z) d z
$$

[29] Finally, given the volume fraction $\left(F_{j}\right)$ of each subinterval in the particle size distribution, the total depth average suspended sediment concentration may be found from,

$$
\bar{C}=\sum_{j}\left(\bar{C}_{j} F_{j}\right)
$$

[30] The overall agreement between measured and computed suspended sediment concentration is not as close as that achieved with bed load computations. The main discrepancy includes a consistent overestimation of the measured values in the near bank zone of the right side of XS20 and XS24 in MB1 and MB2. In large part, the overestimation can be related to the assumption of unlimited supply in the computations which is only suitable over the mobile bed layer. Elsewhere most of the computed values fall within the range of measurement error.

[31] Additional verifications included comparison of observed sediment loads versus sediment feed, which showed an agreement to within $5 \%$ of the feed values (Table 2). Table 2 also indicates that the proportion of bed load amounted to $10 \%$ of the total load as expected.

\subsection{Sediment Dynamics and Bed Evolution}

[32] Patterns of sediment transport and bed topography were closely linked to the observed flow patterns. Figure 6 shows the channel bed photographed at the conclusion of the two experiments. The experiment with no vegetation showed dunes close to the left bank, clearly indicating active sediment transport. In the vegetated experiments the pattern was different close to the left bank and consisted of 

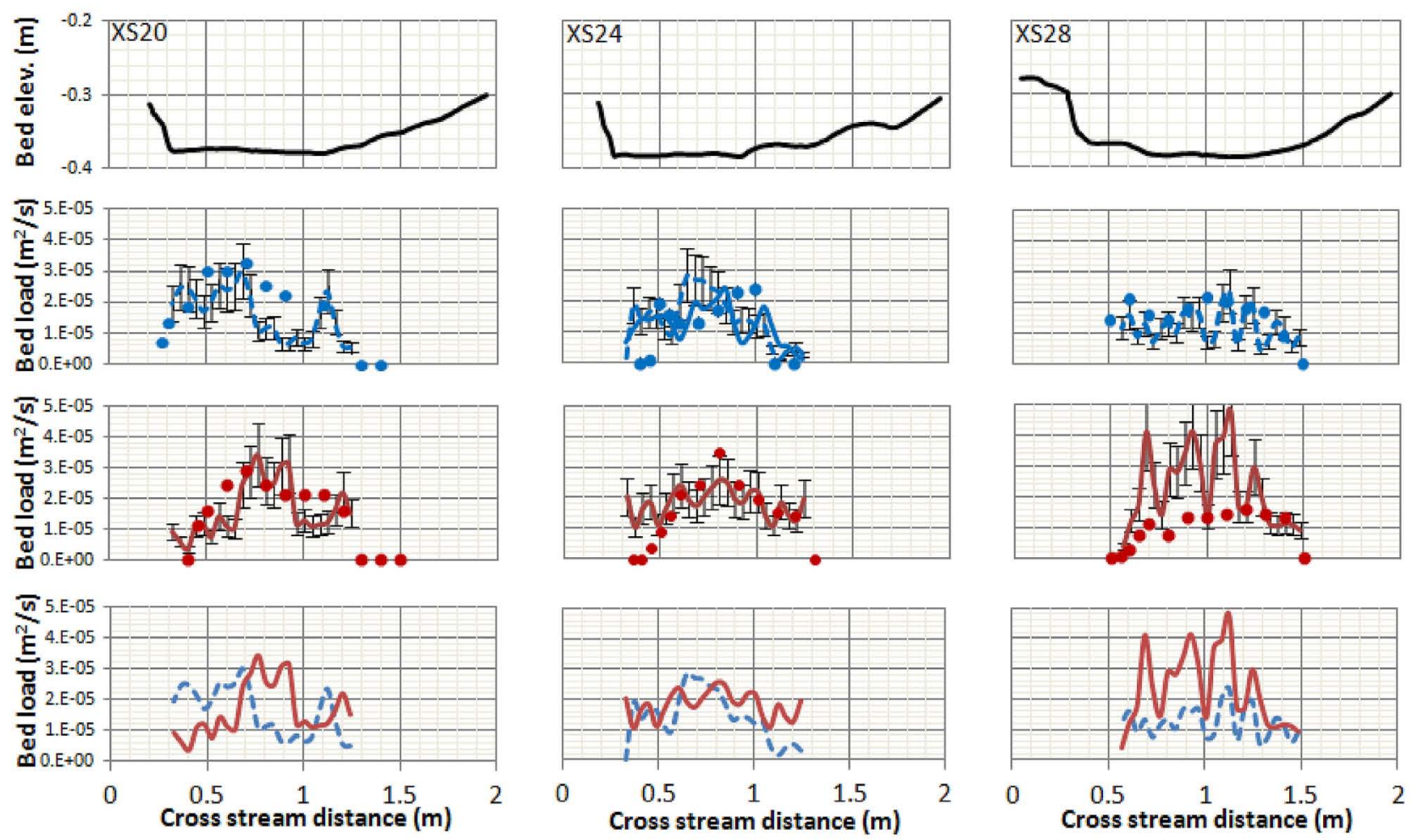

- =- MB1 measured — MB1 measured repeat

- MB1 computed

MB2 measured

- MB2 computed

Figure 10. Bed load transport at XS20, XS24, and XS28, including observed versus computed and MB1 versus MB2. Note the additional measurements at XS24 in MB1 to check repeatability. Error bars represent $\pm 30 \%$ of measured values.

a strip of fine sediment and no dunes, corresponding with the location of reduced bed shear stress. Sediments in the dunes were quite coarse while those in the strip were much finer suggesting suspended sediment deposition.

[33] To investigate sediment dynamics in more detail the various terms comprising equation (4) were computed and shown in Figures 12 and 13 for MB1 and MB2, respectively. Values of the term A, representing the rate of erosion or deposition on the bed, were obtained by computing the slope of a linear fit to the bed profile time series. Positive values indicate deposition or an increase in bed elevation over time. At XS20 for MB1 and MB2, values of term A were similar, except that MB2 had a large deposition zone adjacent to the left bank between $0.35 \mathrm{~m}$ and $0.45 \mathrm{~m}$ along the cross-stream axis. Similarly at XS24 in MB2 a slightly broader deposition zone between $0.3 \mathrm{~m}$ and $0.55 \mathrm{~m}$ could be observed. At XS28 the distributions for MB1 and MB2 were similar, both having a deposition zone over the right bank between 1.1 and $1.5 \mathrm{~m}$. The MB1 experiment had a slightly higher deposition rate.

[34] Terms in equation (4) including suspended sediment fluxes are also shown in Figures 12 and 13 for MB1 and MB2, respectively. The suspended sediment convection terms in equation (4) are denoted B for the downstream direction, $\mathrm{C} 1$ for the component of the cross-stream flux due to divergence or convergence, and $\mathrm{C} 2$ for the component due to secondary circulation. The suspended sediment cross-stream diffusion term is labeled D. Figures 12 and 13 show that the convective fluxes, particularly the B and $\mathrm{C} 1$ terms, are largest while diffusion remains very small. A recurring trend is that the $\mathrm{B}$ and $\mathrm{C} 1$ terms tend to counterbalance each other. In MB 1 at XS20 and XS24 the downstream flux was decreasing near the channel center $(\mathrm{B}>0)$ because of deceleration of flow, which was balanced by an increasing flux toward both banks $(\mathrm{C} 1<0)$. This pattern was reversed at XS28 as the flow and suspended sediment field converged and increased toward the channel center. The effect of secondary circulation $\mathrm{C} 2$ on suspended sediment fluxes was small at XS20 and XS24 but significant at XS28 because of the strong curvature induced cell, resulting in a flux toward the right bank.

[35] Similar patterns of convection were observed in MB2 as shown in Figure 13. Like in MB1, convection was dominated by the $\mathrm{B}$ and $\mathrm{C} 1$ terms, which tended to counterbalance. The diffusion term $\mathrm{D}$ increased slightly in the shear layer zone between 0.3 and $0.5 \mathrm{~m}$ at XS24 where suspended sediment concentrations were high. At XS28 the C2 term was again significant because of the strong curvature induced secondary circulation, which resulted in a flux toward the right bank.

[36] In order to complete the analysis of sediment dynamics based on equation (4), term E, due to bed load fluxes, was also evaluated. Of the two bed load components of term E, only the change in downstream bed load flux was estimated due to available information. An estimate of the cross-streambed load using a steady state mass balance 

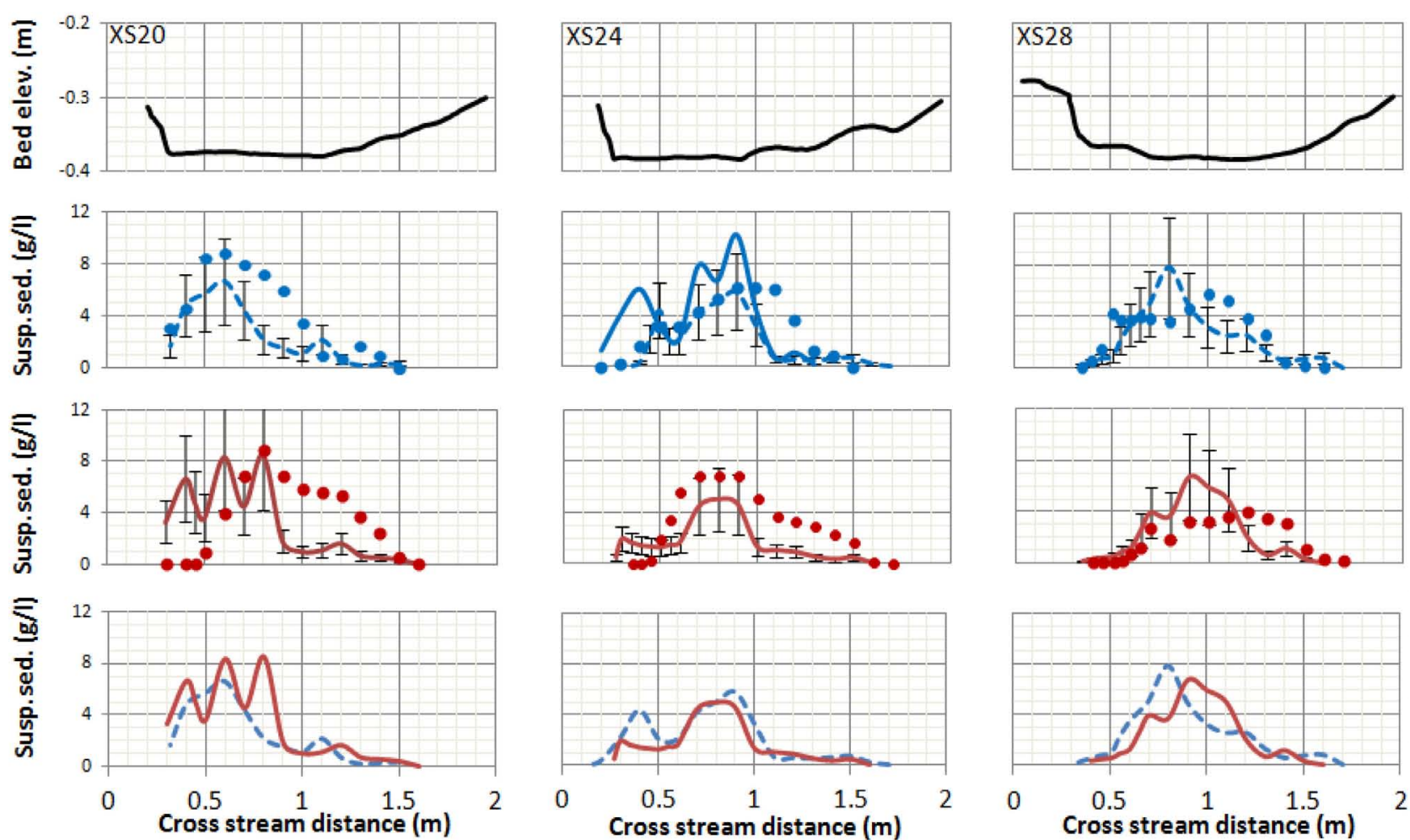

---- MB1 measured $\longrightarrow$ MB1 measured repeat

MB1 computed $\longrightarrow$ MB2 measured

- MB2 computed

Figure 11. Suspended sediment concentration at XS20, XS24, and XS28, including observed versus computed and MB1 versus MB2. Note the additional measurements at XS24 in MB1 to check repeatability. Error bars represent $\pm 50 \%$ of measured values.

following Nelson et al. [2010] indicates it is, at most, 5\% of the downstream bed load component, so the analysis remains meaningful. Term E was calculated as the difference between bed load at consecutive cross sections, divided by the corresponding downstream distance. Additional bed load measurements taken at an upstream section (XS18) in the MB1 experiment were used to compute fluxes at XS20. In order to obtain equivalent information in the MB2 experiment (which lacked the corresponding data at XS18 due to noise contamination), downstream bed load fluxes were computed using the Ashida and Michiue [1972] formulation at XS18 and used to calculate term E at XS20.

Table 2. Proportion of Sediment Transport in Bed Load and Suspended Load With Total Sediment Transport Compared to Upstream Supply

\begin{tabular}{lcccc}
\hline & $Q_{b}\left(\mathrm{~m}^{3} \mathrm{~s}^{-1}\right)$ & $Q_{s}\left(\mathrm{~m}^{3} \mathrm{~s}^{-1}\right)$ & $Q_{b} / Q_{s}(\%)$ & $\left(Q_{t}-Q_{f}\right) / Q_{f}{ }^{\mathrm{a}}(\%)$ \\
\hline & & $M B 1$ \\
XS20 & $1.10 \times 10^{-5}$ & $1.09 \times 10^{-4}$ & 10 & -5.45 \\
XS24 & $1.25 \times 10^{-5}$ & $1.08 \times 10^{-4}$ & 12 & -5.06 \\
XS28 & $1.23 \times 10^{-5}$ & $1.08 \times 10^{-4}$ & 11 & -5.22 \\
& & & & \\
XS20 & $1.19 \times 10^{-5}$ & $1.18 \times 10^{-4}$ & 10 & 5.53 \\
XS24 & $1.57 \times 10^{-5}$ & $1.06 \times 10^{-4}$ & 15 & -4.11 \\
XS28 & $2.21 \times 10^{-5}$ & $1.09 \times 10^{-4}$ & 20 & 3.30 \\
\hline
\end{tabular}

${ }^{\mathrm{a}} Q_{f}$ is the sediment feed rate and equals $1.27 \times 10^{-4} \mathrm{~m}^{3} \mathrm{~s}^{-1} \cdot Q_{t}=$ $Q_{b}+Q_{s}$
[37] Bed load dynamics are shown in Figures 12 and 13 for MB1 and MB2, respectively. At XS20 bed load dynamics were characterized by an increase in transport (term $\mathrm{E}<0$ ) over the left bank and a strong decrease (term $\mathrm{E}>0$ ) at the center for MB1. The trend was reversed at XS24, with transport increasing in the center and decreasing on the sides. At XS28, transport decreased at the center but increased for the first time over the right bank. In MB2 (Figure 13) the distribution of bed load transport tended to be more uniform across the channel compared to MB1. At XS20 transport decreased over the center of the channel and was uniform elsewhere, while smaller changes occurred at XS24. At XS28 transport was more uniform over the right bank than in MB1, and instead increased near the center of the channel.

\section{Discussion}

[38] Flow dynamics were influenced by stream width variation and stream curvature in both the vegetated and unvegetated experiments. Changes in stream width caused the flow to diverge and decelerate at XS20 and XS24, and converge and accelerate at XS28. Streamline curvature generated centrifugal forces toward the outer bank at the bend entrance, which initiated secondary circulation that grew in intensity and width in the downstream direction, fully developing at XS28. At the same time, the centrifugal effects pushed the high-flow velocities and bed shear stresses toward the outer bank. The effect of vegetation 

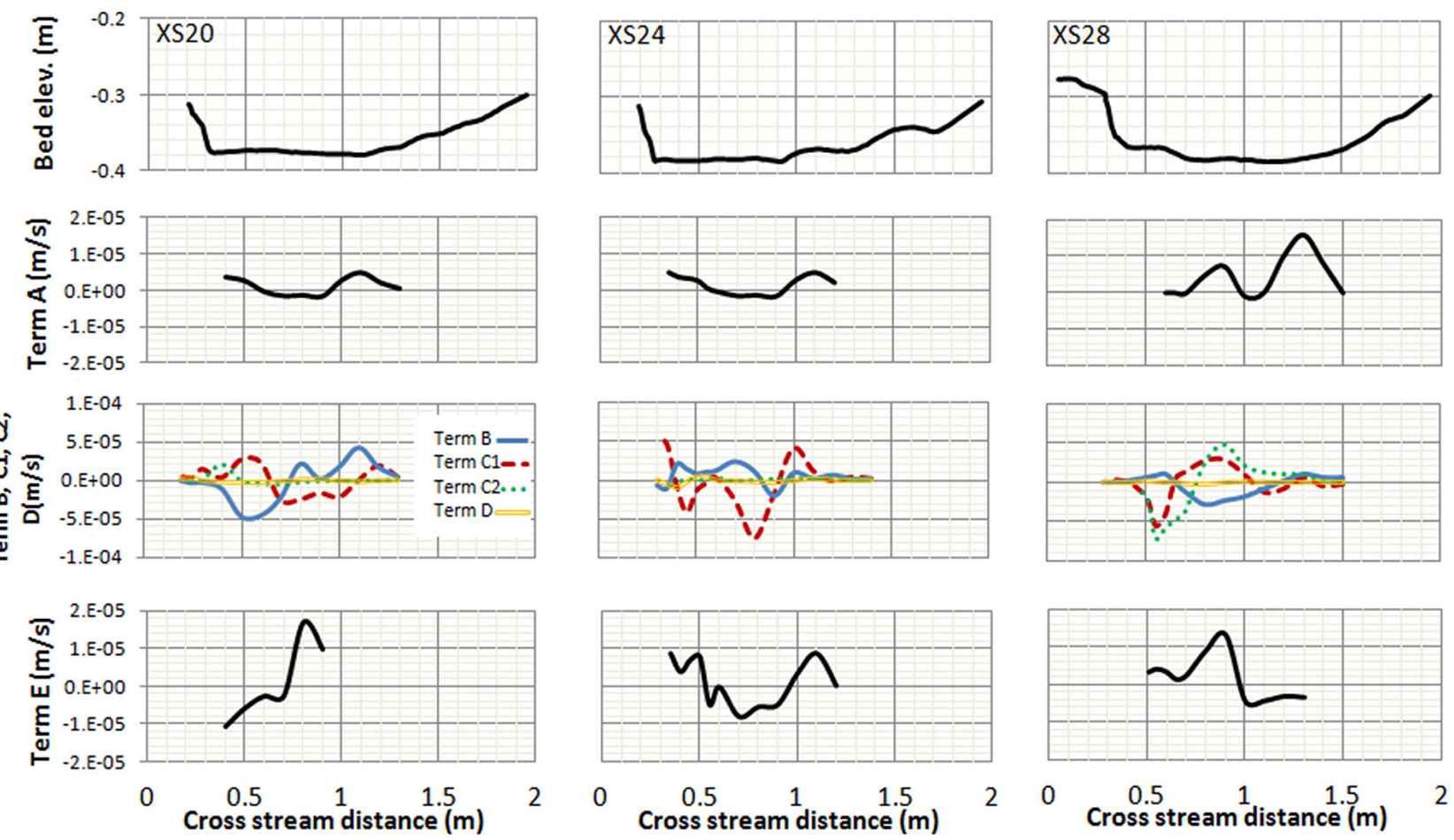

Figure 12. Mass balance components in MB1 at XS20, XS24, and XS28. Term A represents the change in bed elevation over time, with positive values indicating increasing bed elevation. Terms B, $\mathrm{C} 1, \mathrm{C} 2$, and D represent spatial gradients in the following fluxes: downstream convection, cross-stream convection due to convergence or divergence, cross-stream convection due to secondary circulation, and cross-stream diffusion, respectively. Term E represents bed load dynamics, with positive values indicating decreasing bed load with distance downstream.

consisted mainly in keeping the core of high velocity and bed shear stress away from the outer bank and within the central part of the channel [Thorne and Furbish, 1995], effectively straightening the reach streamlines. A clear shear layer with high levels of turbulence developed between the vegetation zone and the main flow area. The width of the shear layer increased and its turbulence levels decreased with downstream distance.

[39] Sediment transport measurements showed consistency when compared to calculated values using transport equations and the flow characteristics discussed above within the margin of measurement error. An overestimation by the transport formulas, exceeding error margins, occurred in side areas of the channel because of the assumption of unlimited supply, which was not always applicable. The agreement between measured and calculated values not only validates the experimental methodology presented herein but also suggests that, under similar conditions to the ones studied here, the use of basic sediment transport formulas, with reliable data on flow and sediment size distribution can give reasonable results, suitable for practical purposes, in the absence of sediment measurements. However, some caution should be exercised in assuming unlimited supply in all parts of the channel. Similarly, both Jordanova and James [2003] and Okabe et al. [1997] found that existing bed load transport formulas developed for much simpler conditions may be extended to vegetated channels providing bed shear stress is accurately partitioned.
[40] In the methodology, the measurements of suspended sediment concentration and bed load were used to compute the terms in equation (4) resulting in a propagation of error, which is considered here before discussing the results of the analysis. As mentioned, the error associated with measurements of suspended sediment concentration was $\pm 50 \%$ and a smaller error of $\pm 10 \%$ was associated with the use of velocities from the fixed bed experiments (Table 1) while a similar percentage error is given to the diffusivity. These errors are then propagated into the terms B, C1, C2, and D. The propagated error using Gaussian error propagation [Barry, 1978], is $\pm 51 \%$, but most importantly, it is the same for terms B, C1, C2, and D as each relies on the same measurement of suspended sediment concentration. Thus the relative magnitude of each term, which is the subject of discussion, should remain the same even if more precise measurements were obtained. The error associated with term $\mathrm{E}$ is likely to be larger than the bed load measurement error of $\pm 30 \%$ because of approximation of the term between cross sections located a considerable distance apart.

[41] The mass balance considerations, presented in Figures 12 and 13 can be used to infer how the transport mechanisms, may be related to morphological changes. For instance, downstream convection (term B) is expected to have very different depositional patterns in expansions (decelerating flow) or contractions (accelerating flow). In an expansion, central deposition can be expected depending on the balance between downstream and primary cross-stream 

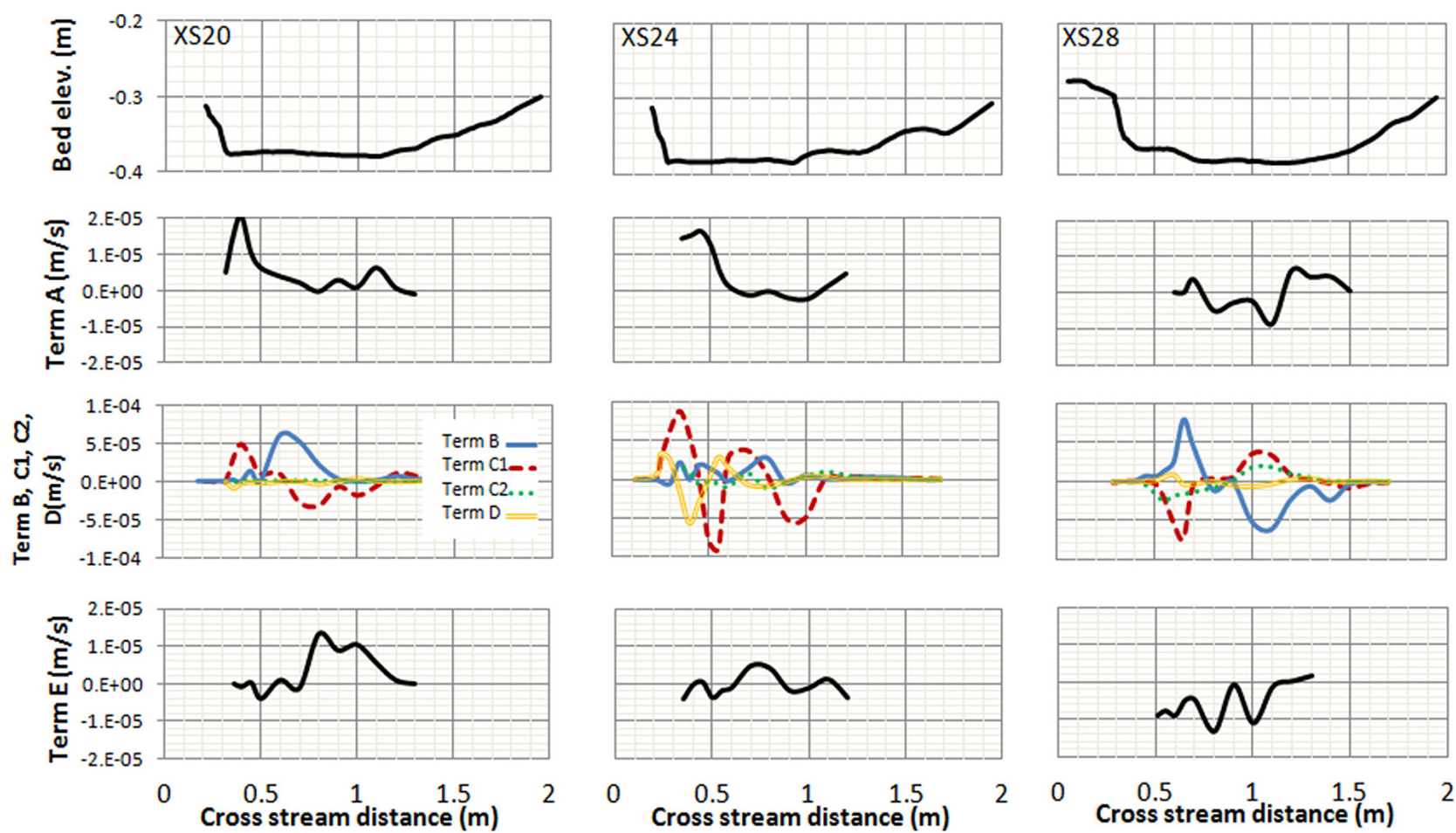

Figure 13. Mass balance components in MB2 at XS20, XS24, and XS28. Term A represents the change in bed elevation over time, with positive values indicating increasing bed elevation. Terms B, $\mathrm{C} 1, \mathrm{C} 2$, and D represent spatial gradients in the following fluxes: downstream convection, cross-stream convection due to convergence or divergence, cross-stream convection due to secondary circulation, and cross-stream diffusion, respectively. Term E represents bed load dynamics, with positive values indicating decreasing bed load with distance downstream.

convection (terms B and C1). Generally downstream convection will generate central deposition and cross-stream convection will redistribute sediment from the center toward the banks. In a contraction, downstream convection will generate central erosion and cross-stream convection will redistribute sediment toward the center from the banks. In the current experiments a counterbalance of $\mathrm{B}$ and $\mathrm{C} 1$ was consistently observed in XS20 and XS28 for all experiments. XS20 was clearly in an expansion, where B generated central overloading that was distributed laterally to the sides by $\mathrm{C} 1$. At XS28 the flow contracted and the central underloading, associated with $\mathrm{B}$, was compensated by the $\mathrm{C} 1$ fluxes from the banks. The weakening of the expansion at XS24 made the balance of fluxes less straightforward in both unvegetated and vegetated experiments. These results show that simple convergence and divergence patterns, which control the dynamics of large braided rivers with B/H > 100 [McLelland et al., 1999; Parsons et al., 2007] can be effective in smaller rivers with $\mathrm{B} / \mathrm{H}$ varying between 20 to 30 .

[42] Where streamwise curvature was strongest, the dominant transverse flux switched to secondary crossstream convection (term $\mathrm{C} 2$ ). The secondary convection also has a characteristic morphological pattern, which consists of deposition in the areas of ascending near-bed flow and erosion in the downwelling areas. For curvatureinduced secondary circulation cells that occupy most of the cross section, deposition occurs on the inner bank and erosion on the outer. Accordingly, XS20 showed small positive $\mathrm{C} 2$ values associated with deposition on the left bank because of residual secondary flow at the curve entrance, whereas XS28 showed a pattern of erosion close to the left bank and deposition close to the right bank consistent with the fully developed secondary circulation.

[43] The cross-stream diffusion (term D) was relatively small in all experiments, even in the vegetated experiments where larger fluxes were observed in the shear layer. The difference in magnitude between the convective and diffusive fluxes shows that fairly mild stream curvature and variable channel width result in convective fluxes which are far more substantial than the diffusive fluxes. Other studies tend to emphasize diffusive fluxes because their straight channel configurations prevent any transverse convective flux [Ikeda et al., 1991; Sharpe and James, 2006; Zong and Nepf, 2010].

[44] Bed load fluxes were an order of magnitude smaller than suspended sediment fluxes. Despite the difference in magnitude, the bed load fluxes of term E had the expected opposite trend to suspended sediment fluxes that follows from equation (4), most notably at XS20 and XS28. At XS20 there was a deficit of suspended sediment $(B+C 1+$ $\mathrm{C} 2+\mathrm{D}<0)$ in the center of the channel which was partly compensated by bed load overloading $(\mathrm{E}>0)$. Likewise at $\mathrm{XS} 28$ a deficit on the left side of the channel $(\mathrm{B}+\mathrm{C} 1+\mathrm{C} 2+$ $\mathrm{D}<0$ ), was somewhat compensated by a overloading of bed load coming from XS24. The pattern of bed load at 
expansions (XS20) and contractions (XS28) agrees with results from Repetto et al. [2002].

[45] The effects of introduced vegetation in the present experiments can be assessed by focusing on the differences in fluxes and depositional patterns among MB1 and MB2. Even though some general patterns were maintained, MB2 showed notable differences to the change in bed elevation over time (term A) measured in MB1. At XS20 and XS24 the region of the bed closer to the left bank was increasing at a much higher rate than in MB1 (maximum rate of 0.02 $\mathrm{mm} \mathrm{s} \mathrm{s}^{-1}$ ). This can be explained noting that vegetation along the left bank directly impacts the downstream convection of suspended sediment (term $B$ ) reducing it to zero in the near bank zone. The balance of B with the primary cross-stream convection (term C1) no longer applies, resulting in $\mathrm{C} 1$ generating overloading and increased deposition. The main flux associated with this increased deposition is then $\mathrm{C} 1$, clearly dominant over the left bank and notably bigger in the vegetated experiments both at XS20 and XS24. There was also a contribution from the secondary cross-stream convection (term $\mathrm{C} 2$ ), but it remained at about the same level in the vegetated and unvegetated experiments. Cross-stream diffusion (term D) was only present in the vegetated experiments but was smaller than $\mathrm{C} 1$ and essentially redistributed sediment within the shear layer.

[46] The effects of vegetation also extended to the opposite (right) bank of XS28. Here the rate of deposition associated with the $\mathrm{C} 2$ flux was noticeably less than in the unvegetated case. This difference can be explained by the smaller magnitude of secondary flow in the vegetated case due to an overall straightening of the flow path. Thus, bank vegetation had a local effect of inducing sedimentation near the outer bank but also reduced deposition farther downstream along the inner bank because of the suppression of secondary circulation. This shows that vegetation along the outer bank may dampen or even reverse the normal sediment dynamics of meandering rivers i.e., erosion along the outer bank and deposition along the inner bank.

[47] Vegetation is often used in river restoration projects for its ability to locally increase bank protection and sediment capture. However, it is less fully appreciated that vegetation can have significant effects on an entire river reach. In regard to the specific field site, our observations suggest there will be an increase in fine sediment deposition and capture brought about by revegetation, which will most likely be considered beneficial for rehabilitation. However, the reduction in stream curvature is likely to be considered less beneficial as it is important for maintaining different bed forms and natural stream processes. Therefore this research suggests that some consideration should be given to these reach-scale effects in restoration projects using vegetation in various spatial distributions. The likely impacts on reach-scale morphology could be predicted by 2-D hydrodynamic modeling alone, as the changes in sediment transport fluxes tend to follow the main hydrodynamic patterns as found in these experiments and others [Bennett et al., 2008]. More generally, the current experiments provide an interesting comparison to those of Bennett et al. [2002] which showed the ability of alternate patches to initiate meandering and thus restore artificially straightened streams. The current experiments on the other hand show that vegetation coverage along the outer banks can straighten a meandering stream. Hence the two experiments provide contrasting responses of reach-scale flow and sediment dynamics to vegetation.

\section{Conclusions}

[48] The laboratory experiments presented herein have been designed to better understand the flow and sediment dynamics of a mildly sinuous, variable width sand bed stream and the effects of introduced riparian vegetation on the outer bank. Field characteristics of an existing stream reach undergoing restoration have been used in the experimental design. The stream has a mixed load, variation in channel width and curvature with signs of erosion along the outer bank.

[49] The methodology involved measurement of flow characteristics in a fixed bed stage and sediment transport and concentration in movable bed stage with and without vegetation. Combination of data from both stages was possible because of the similarity of flow patterns. It was generally observed that sediment transport in the mobile bed stage followed the patterns of bed shear stress in the fixed bed stage.

[50] Very few field or laboratory studies have carried out a complete analysis of the sediment continuity equation in streams with natural morphology. This study was able to perform an analysis of the sediment continuity equation from laboratory measurements in a channel with natural morphology. The largest fluxes were the longitudinal and transverse convection of suspended sediment. The transverse convection pattern had two components which are controlled by stream morphology. Variations in stream width led to strong convergence and divergence patterns, which have the potential to generate zones of central erosion and deposition, respectively. Where stream curvature was highest the dominant convective flux switched to secondary circulation which generated alternate erosion and deposition zones. It was also concluded that the straight channel configurations of many experiments may tend to exaggerate the impact of transverse diffusion, which was markedly smaller than convective processes in the current experiments.

[51] The sediment continuity equation was again used to analyze the impact of vegetation. It was found that vegetation along the outer bank had an immediate impact of reducing the downstream convection of suspended sediment. This disrupted the balance with the transverse convective flux causing overloading and increased deposition along the outer bank. In addition, the straightening of the flow path and suppression of secondary currents resulted in decreased deposition on the inner bank of the bend. From these observations it is suggested that outer bank vegetation may reverse the normal dynamics of meandering streams where erosion occurs along the outer bank and deposition along the inner bank [Ikeda and Nishimura, 1985].

[52] The current experiments also provide an interesting comparison to those of Bennett et al. [2002]. In their experiments alternate vegetation patches, acting as point bars, were able to initiate meandering from an initially straight channel. In contrast, the current experiment showed the ability of vegetation, distributed along the outer bank to 
have a straightening effect on flow and sediment dynamics. Therefore, very different responses arise from contrasting spatial distributions of vegetation within the channel. From a management perspective, flow and sediment dynamics were found to strongly impact the entire modeled reach, not just the vegetated area. It is therefore suggested that restoration projects similar to one underway would benefit from a prior two dimensional assessment of the impact of restorative vegetation at the reach scale.

[53] Acknowledgments. This research was supported by grant LP 0455476 from the Australian Research Council. Additional financial assistance was received from the New South Wales Office of Water, the Tom Farrell Institute for the Environment, and the Faculty of Engineering and Built Environment at the University of Newcastle. The authors are grateful for the assistance of laboratory staff and undergraduate students at the University of Newcastle, who assisted in the collection of data. J. Abad and two anonymous reviewers provided valuable feedback that helped improve the paper.

\section{References}

Ashida, K., and M. Michiue (1972), Study on hydraulic resistance and bedload transport rate in alluvial streams, Trans. Jpn. Soc. Civ. Eng., 206, 59-62.

Barry, B. A. (1978), Errors in Practical Measurement in Science, Engineering and Technology, Wiley-Interscience, New York.

Bennett, S. J., T. Pirim, and B. D. Barkdoll (2002), Using simulated emergent vegetation to alter stream flow direction within a straight experimental channel, Geomorphology, 44, 115-126.

Bennett, S. J., W. M. Wu, C. Alonso, and S. S. Y. Wang (2008), Modeling fluvial response to in-stream woody vegetation: Implications for stream corridor restoration, Earth Surf. Processes Landforms, 33, 890-909, doi: $10.1002 /$ esp. 1581 .

Bettess, R. (1990), Survey of lightweight sediments for use in mobile-bed physical models, in Movable Bed Physical Models, edited by H. W. Shen, pp. 115-123, Kluwer Acad., Dordrecht, Netherlands.

Binns, A. D., and A. M. F. da Silva (2009), On the quantification of the bed development time of alluvial meandering streams, J. Hydraul. Eng., 135 , 350-360, doi:10.1061/(ASCE)HY.1943-7900.0000025.

Dade, W. B., and P. F. Friend (1998), Grain-size, sediment-transport regime, and channel slope in alluvial rivers, J. Geol., 106, 661-675.

Engelund, F., and E. Hansen (1967), A monograph on sediment transport in alluvial streams, TekniskForlag, Copenhagen.

Garcia, M. H. (1999), Sedimentation and erosion hydraulics, in Hydraulic Design Handbook, edited by L. W. Mays, pp. 6.1-6.107, McGraw-Hill, New York.

Garcia, M. H. (2008), Sediment transport and morphodynamics, in Sedimentation Engineering: Processes, Measurements, Modeling, and Practice, edited by M. H. Garcia, pp. 21-146, Am. Soc. of Civ. Eng., Reston, Va.

Garcia, M. H., and G. Parker (1991), Entrainment of bed sediment into suspension, J. Hydraul. Eng., 117, 414-435.

Gorrick, S. (2011), Flow and sediment dynamics in sand bed streams with riparian vegetation, $\mathrm{PhD}$. thesis, School of Engineering, Univ. of Newcastle, Australia.

Gran, K., and C. Paola (2001), Riparian vegetation controls on braided stream dynamics, Water Resour. Res., 37, 3275-3283, doi:10.1029/ 2000WR000203.

Ikeda, S., and T. Nishimura (1985), Bed topography in bends of sand-silt rivers, J. Hydraul. Eng., 111, 1397-1411.

Ikeda, S., N. Izumi, and R. Ito (1991), Effects of pile dikes on flow retardation and sediment transport, J. Hydraul. Eng., 117, 1459-1478.

Jordanova, A. A., and C. S. James (2003), Experimental study of bed load transport through emergent vegetation, J. Hydraul. Eng., 129, 474-478, doi:10.1061/(ASCE)0733-9429(2003)129:6(474).
Lane, S. N., P. M. Biron, K. F. Bradbrook, J. B. Butler, J. H. Chandler, M. D. Crowell, S. J. McLelland, K. S. Richards, and A. G. Roy (1998), Three-dimensional measurement of river channel flow processes using acoustic Doppler velocimetry, Earth Surf. Processes Landforms, 23, 1247-1267.

Lopez, F., and M. Garcia (1998), Open-channel flow through simulated vegetation: Suspended sediment transport modeling, Water Resour. Res., 34, 2341-2352.

McLelland, S. J., P. J. Ashworth, J. L. Best, J. Roden, and G. J. Klaassen (1999), Flow structure and transport of sand-grade suspended sediment around an evolving braid bar, Jamuna River, Bangladesh, in Fluvial Sedimentology VI, edited by N. D. Smith and J. Rogers, Spec. Publ. Int. Assoc. Sedimentol., 28, 43-57.

Nelson, J. M., and J. D. Smith (1989), Flow in meandering channels with natural topography, in River Meandering, Water Resour. Monogr., vol. 12, edited by S. Ikeda and G. Parker, pp. 69-102, AGU, Washington, D. C.

Nelson, P. A., W. E. Dietrich, and J. G. Venditti (2010), Bed topography and the development of forced bed surface patches, J. Geophys. Res., 115, F04024, doi:10.1029/2010JF001747.

Okabe, T., T. Yuuki, and M. Kojima (1997), Bed-load rate on movable beds covered by vegetation, paper presented at 27th Congress of the IAHR, Int. Assoc. of Hydraul. Res., San Francisco, Calif.

Parker, G. (1978), Self-formed straight rivers with equilibrium banks and mobile bed. Part 1. The sand-silt river, J. Fluid Mech., 89, 109-125.

Parsons, D. R., J. L. Best, S. N. Lane, O. Orfeo, R. J. Hardy, and R. Kostaschuk (2007), Form roughness and the absence of secondary flow in a large confluence-diffluence, Rio Parana, Argentina, Earth Surf. Processes Landforms, 32, 155-162.

Perucca, E., C. Camporeale, and L. Ridolfi (2007), Significance of the riparian vegetation dynamics on meandering river morphodynamics, Water Resour. Res., 43, W03430, doi:10.1029/2006WR005234.

Repetto, R., M. Tubino, and C. Paola (2002), Planimetric instability of channels with variable width, J. Fluid Mech., 457, 79-109, doi:10.1017/ S0022112001007595.

Rhoads, B. L., and S. T. Kenworthy (1998), Time-averaged flow structure in the central region of a stream confluence, Earth Surf. Processes Landforms, 23, 171-191.

Rodríguez, J. F., and M. H. García (2008), Laboratory measurements of 3-D flow patterns and turbulence in straight open channel with rough bed, J. Hydraul. Res., 46, 454-465, doi:10.3826/jhr.2008.2994.

Rominger, J. T., A. F. Lightbody, and H. M. Nepf (2010), Effects of added vegetation on sand bar stability and stream hydrodynamics, J. Hydraul. Eng., 136, 994-1002, doi:10.1061/(ASCE)HY.1943-7900. 0000215 .

Sharpe, R. G., and C. S. James (2006), Deposition of sediment from suspension in emergent vegetation, Water $S A, 32,211-218$.

Shimizu, Y., and T. Tsujimoto (1997), Suspended sediment concentration affected by organised motion near vegetation zone, paper presented at 27th Congress of IAHR, Int. Assoc. of Hydraul. Res., San Francisco, Calif.

Thorne, S. D., and D. J. Furbish (1995), Influences of coarse bank roughness on flow within a sharply curved river bend, Geomorphology, 12, 241-257, doi:10.1016/0169-555X(95)00007-R

Wright, S., and G. Parker (2004), Flow resistance and suspended load in sand-bed rivers: Simplified stratification model, J. Hydraul. Eng., 130, 796-805.

Yuuki, T., and T. Okabe (1997), Influence of vegetation on hydrogeomorphic process of alternating bars, paper presented at 27th Congress of the IAHR, Int. Assoc. of Hydraul. Res., San Francisco, Calif.

Zong, L., and H. Nepf (2010), Flow and deposition in and around a finite patch of vegetation, Geomorphology, 116, 363-372, doi:10.1016/ j.geomorph.2009.11.020.

S. Gorrick and J. F. Rodríguez, University of Newcastle Australia, Callaghan, NSW 2308, Australia. (jose.rodriguez@newcastle.edu.au) 